\title{
Proton therapy for breast cancer: progress \& pitfalls
}

\author{
Kimberly S Corbin ${ }^{1}$ \& Robert W Mutter*,1 \\ ${ }^{1}$ Department of Radiation Oncology, Mayo Clinic, Rochester, MN 55905, USA \\ *Author for correspondence: Tel.: +1 507284 8227; Fax: +1 507284 0079; mutter.robert@mayo.edu
}

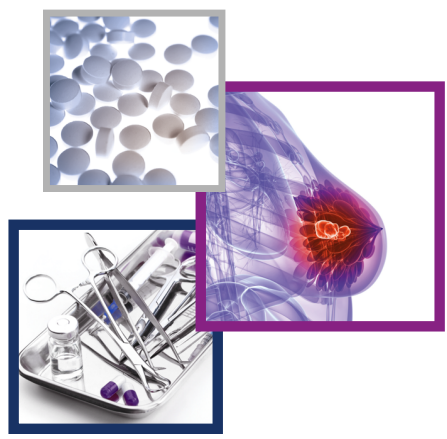

\section{Practice points}

- Proton therapy is under investigation for early stage and locally advanced breast cancer.

- Due to unique physical properties, proton therapy reduces the dose to the heart, lungs, skin, muscle, and bone and is therefore hypothesized to reduce side effects from treatment.

- Proton therapy may also enable improved target coverage in some breast cancer patients.

- Due to its highly conformal nature, proton therapy requires careful attention to target volume delineation and implementation of strategies to mitigate uncertainties in setup and delivery.

- Proton therapy for breast cancer is rapidly evolving with improvements in techniques for treatment delivery and optimizing of dose and fractionation schedules.

- Research is ongoing to determine whether proton therapy improves treatment outcomes and quality of life compared with conventional photon techniques.

As the number of patients cured from breast cancer increases with improvements in multidisciplinary care, emphasis on reducing late toxicities of treatment has increased, in order to improve long-term quality of life. Proton beam therapy (PBT) is a form of radiotherapy that uses particles with unique physical properties that enable treatment delivery with minimal dose deposition beyond the treatment target. Therefore, PBT has emerged as an exciting radiotherapy modality for breast cancer due to the ability to minimize exposure to the heart, lungs, muscle, and bone. Herein, we review the rationale for PBT in breast cancer, potential clinical applications, and the available clinical data supporting its use. We also address some of the technical and logistical challenges and areas of ongoing research that will ultimately establish the role for PBT for breast cancer in the years ahead.

First draft submitted: 5 January 2018; Accepted for publication: 13 March 2018; Published online: 13 April 2018

Keywords: breast cancer $\bullet$ cardiotoxicity $\bullet$ heart $\bullet$ particle therapy $\bullet$ pencil-beam scanning $\bullet$ proton therapy • radiation therapy

Breast cancer accounts for 30\% of new cancer diagnoses in women [1]. Although breast cancer remains the second leading cause of cancer death among women, advances in detection and treatment have resulted in improved outcomes, with 5-year expected survival of 90\% [1]. Radiation therapy (RT) is indicated in the management of the majority of women with breast cancer [2]. For early stage breast cancer, breast irradiation following lumpectomy is an essential component of breast conserving therapy, lowering the risk of recurrence and improving breast cancer specific survival $[3,4]$. Recently published clinical trials also support the oncologic value of regional nodal irradiation (RNI) in some women with high risk node negative or axillary nodal metastases [5,6]. In addition, women with locally advanced breast cancer benefit from RT to the chest wall and regional lymph nodes, delivered in the post mastectomy setting [7].

While RT is widely utilized and improves breast cancer treatment outcomes, RT is also associated with late effects including cardiopulmonary toxicity, lymphedema and secondary malignancy [8-10]. As the number of patients cured from breast cancer increases with improvements in multidisciplinary care, emphasis on reducing late therapeutic toxicity has increased, in order to improve long-term quality of life [11]. For each region at risk of harboring microscopic disease, radiation oncologists must carefully weigh the benefits of treatment against the potential harms of normal tissue exposure. Compared with years past, improved technologies now enable more 
precise delivery of RT with potential to improve the therapeutic ratio. The emergence of proton beam therapy (PBT), which is under investigation in patients with breast cancer, is one such advance. Because of unique physical properties, PBT not only reduces nontarget normal tissue exposure, but also may improve target coverage of difficult to treat areas such as the internal mammary nodes (IMNs), which lie adjacent to the heart and lungs. Therefore, PBT represents a promising approach to improve long-term treatment outcomes. Simultaneously, due to the sophistication and scale of equipment necessary to accelerate protons for use in cancer therapy, PBT can be more costly than conventional photon therapy, and PBT is accompanied by unique technical challenges. The aim of this review is to discuss the burgeoning role of PBT in the management of breast cancer.

\section{Rationale for proton therapy in breast cancer}

\section{Characteristics of proton therapy}

Megavoltage $\mathrm{x}$-ray therapy is the most widespread form of external beam RT used in the clinic to treat cancer. With megavoltage $\mathrm{x}$-rays or photons, the radiation dose falls off gradually with depth, resulting in collateral exposure of normal tissues both proximal and distal to the targeted disease. In contrast, protons stop at a well-defined depth, and the dose deposition of protons reaches a maximum near the end of the proton range. This rapid energy loss at the end of the proton range, the so-called Bragg Peak, results in less dose deposition in normal tissues both proximal and distal to the target [12]. The depth of PBT tissue penetration depends on the energy produced by the proton accelerator, with higher energy protons having a greater range than low energy protons. Target volumes are treated in the clinic by superposition of beam of protons with high enough energy to cover the distal end of the target volume with beams of decreasing energy in order to create a region of uniform dose over the entire target volume. The sum of these beams of varying energies is called the spread-out Bragg peak (SOBP). These unique physical characteristics of protons provide an opportunity to improve the therapeutic ratio of RT across multiple malignancies, including breast cancer.

\section{Potential to reduce toxicity Cardiac}

Radiation exposure to the heart increases the risk of delayed cardiac toxicity [13]. In the Early Breast Cancer Trialists' collaborative group meta-analysis of individual patient data from breast cancer randomized controlled trials initiated prior to 1995, the breast cancer mortality benefit of RT was partially off-set by an increased risk of cardiac mortality. In that study, RT was associated with an estimated 1.27-fold increase in cardiac events and a 1.12-fold increase in cardiac mortality [7,14]. Darby et al. reported long-term follow-up of a population-based cohort of women with breast cancer irradiated between 1958 and 2001 in Sweden and Denmark and also demonstrated an increased risk of cardiac events and mortality over time following RT [15]. Importantly, the rate of major coronary events increased linearly with mean heart dose, with an estimated 7.4\% relative increase per Gy. In addition, there was no definite threshold under which no risk was observed. This linear relationship between mean heart dose and cumulative incidence of cardiac events has been validated in a recent cohort [16]. Therefore, there is strong evidence to support efforts to limit even low dose cardiac exposure. Of note, the absolute risks of cardiac toxicity from RT appear higher in smokers [17] and patients with other cardiac risk factors including receipt of potentially cardiotoxic chemotherapy agents commonly used for the treatment of breast cancer. There are many parameters we do not yet understand about cardiac risk from RT, including importance of dose to cardiac substructures, mechanism of injury and which dose parameters are most meaningful [18]. However, based on current models and typical dose metrics achieved with PBT, as shown in Table 1, significant reductions in late cardiac toxicity would be expected for many patients compared with advanced photon planning $[17,19,20]$.

\section{Pulmonary}

Radiation pneumonitis is a potential complication of breast cancer RT and has been correlated with lung dose and the volume of lung exposed [21]. Recent evidence also supports a relationship between lung exposure and future risk of secondary lung cancer [17]. Like cardiac toxicity, this risk is enhanced by cigarette smoking [22,23], suggesting that current and former smokers may have the greatest absolute benefit from reducing lung doses with PBT.

\section{Musculoskeletal}

Compared with photon therapy, PBT reduces exposure of the skin, muscle and bone, particularly in patients undergoing RNI (Figure 1). Whether these dose reductions will ultimately reduce musculoskeletal complications 


\begin{tabular}{|c|c|c|c|c|c|}
\hline Study & Population & Modalities compared & Mean heart dose (Gy) & Mean heart V20 (\%) ${ }^{\dagger}$ & $\begin{array}{l}\text { Mean ipsilateral lung V20 } \\
\text { (\%) }\end{array}$ \\
\hline Patel et al. & $\begin{array}{l}10 \text { left-sided PMRT } \\
\text { patients with unfavorable } \\
\text { cardiac anatomy }\end{array}$ & $\begin{array}{l}\text { 3D photon DIBH } \\
\text { PS proton FB } \\
\text { PBS proton FB } \\
\text { PBS proton DIBH }\end{array}$ & $\begin{array}{l}\text { 2.1 Photon } \\
0.4 \text { PS proton } \\
\text { 1.0 PBS FB } \\
\text { 0.7 PBS DIBH }\end{array}$ & $\begin{array}{l}\text { 2.7 Photon } \\
0.03 \text { PS proton } \\
\text { 0 PBS FB } \\
\text { 0 PBS DIBH }\end{array}$ & $\begin{array}{l}\text { 26.0 Photon } \\
\text { 12.0 PS proton } \\
\text { 15.2 PBS FB } \\
\text { 14.4 PBS DIBH }\end{array}$ \\
\hline Mast et al. & $\begin{array}{l}20 \text { left- sided whole } \\
\text { breast RT patients }\end{array}$ & $\begin{array}{l}\text { PBS proton DIBH } \\
\text { PBS proton FB } \\
\text { IMRT photon DIBH } \\
\text { IMRT photon }\end{array}$ & $\begin{array}{l}0.1 \text { proton } \mathrm{DIBH} \\
0.2 \text { proton FB } \\
1.5 \text { IMRT DIBH } \\
2.7 \text { IMRT FB }\end{array}$ & $\begin{array}{l}0 \text { proton DIBH } \\
0 \text { proton FB } \\
0.6 \text { IMRT DIBH } \\
3.5 \text { IMRT FB }\end{array}$ & $\begin{array}{l}2.5 \text { proton DIBH } \\
2.8 \text { proton FB } \\
\text { 10.9 IMRT DIBH } \\
12.4 \text { IMRT FB }\end{array}$ \\
\hline Lin et al. & $\begin{array}{l}10 \text { left-sided whole breast } \\
\text { RT patients }\end{array}$ & $\begin{array}{l}\text { PBS proton } \\
\text { US proton } \\
\text { IMRT photon }\end{array}$ & $\begin{array}{l}0.01 \text { PBS proton } \\
0.009 \text { US proton } \\
1.6 \text { IMRT }\end{array}$ & $\begin{array}{l}0 \text { PBS proton } \\
0 \text { US proton } \\
0.7 \text { IMRT }\end{array}$ & $\begin{array}{l}0 \text { PBS proton } \\
2.5 \text { PS proton } \\
12.5 \text { IMRT }\end{array}$ \\
\hline Xu et al. & $\begin{array}{l}10 \text { left-sided PMRT } \\
\text { patients }\end{array}$ & $\begin{array}{l}\text { Photon + proton } \\
\text { Photon only } \\
\text { IMRT }\end{array}$ & $\begin{array}{l}1 \text { photon + proton } \\
3 \text { photon only } \\
5 \text { IMRT }\end{array}$ & $\begin{array}{l}0 \text { photon + proton } \\
4 \text { photon only } \\
21 \text { IMRT }\end{array}$ & $\begin{array}{l}31 \text { photon + proton } \\
36 \text { photon only } \\
30 \text { IMRT }\end{array}$ \\
\hline Fagundes et al. ${ }^{\dagger}$ & $\begin{array}{l}10 \text { left-sided PMRT } \\
\text { patients }\end{array}$ & $\begin{array}{l}\text { Proton } \\
\text { IMRT } \\
\text { photon arc based HT } \\
\text { 3D photon }\end{array}$ & $\begin{array}{l}1.2 \text { proton } \\
8.2 \mathrm{IMRT} \\
10.2 \mathrm{HT} \\
6.8 \text { photon }\end{array}$ & $\begin{array}{l}1.2 \text { proton } \\
7.4 \mathrm{IMRT} \\
7.9 \mathrm{HT} \\
6.8 \mathrm{BD}\end{array}$ & $\begin{array}{l}\text { Mean total lung reported, } \\
\text { favored proton therapy }\end{array}$ \\
\hline Ares et al. & $\begin{array}{l}20 \text { left-sided breast } \\
\text { patients, with } \\
\text { CW/WB }+/- \text { nodes }\end{array}$ & $\begin{array}{l}\text { PBS proton } \\
\text { IMRT photon } \\
\text { 3D photon }\end{array}$ & $\begin{array}{l}\text { Without/with nodes: } \\
1 / 1 \text { PBS } \\
12 / 16 \text { IMRT } \\
9 / 15 \text { photon }\end{array}$ & Not reported & $\begin{array}{l}\text { Without/with nodes: } \\
\text { 7/15 PBS } \\
\text { 10/22 IMRT } \\
\text { 16/39 photon }\end{array}$ \\
\hline
\end{tabular}

${ }^{\dagger}$ Fagundes reports V25 heart.

BCS: Breast conserving surgery; CW/WB: Chest wall/whole breast irradiation; DIBH: Deep inspiratory breath hold; FB: Free breathing; HT: Helical tomotherapy; IMRT: Intensity modulated radiation therapy; LV: Left ventricle; PBS: Pencil beam scanning proton; PMRT: Post mastectomy; PS: Passive scattered; US: Uniform scanning; V20: The volume receiving 20 Gy or more.

is an important area of investigation. Of note, RNI with photons has been correlated with painful muscle and joint fibrosis which inhibits range of motion and shoulder function [24]. In addition, RT can lead to focal osteopenia. Therefore, by reducing dose to soft tissues and bone, PBT is hypothesized to reduce the future risk of these complications [25].

\section{Second malignancy}

RT for breast cancer results in a small absolute increased risk of secondary malignancy. A recent SEER database study found an excess of 1.1 secondary malignancies per 100 BC patients who survive 10 years, although just $3.4 \%$ of these were attributable to radiation [26]. The risk of secondary malignancy has been associated with age (with irradiation at a younger age being at higher risk), length of follow-up, dose and volume of tissue irradiated [27].

Intensity modulated radiation therapy (IMRT) is an alternative technique to conventional photon planning that improves the ability to conform RT to the target volume while reducing medium to high dose exposure of normal tissues. However, the potential cost is greater low dose spread over a larger volume of tissue, resulting in higher integral dose. Because induction of secondary malignancy has no apparent threshold, there is concern that the long-term risk of second cancer from breast RT may be higher with IMRT [28]. One recent SEER analysis demonstrated an excess risk of secondary solid tumors to tissues receiving $>1$ Gy of exposure [29]. Thus, limiting whole body integral dose with PBT may reduce long-term risks of secondary cancers, particularly over IMRT [30].

\section{Improved target volume coverage}

Given these and other potential toxicities of treatment, radiation oncologists may compromise coverage of areas at risk of harboring microscopic breast cancer in order to minimize dose to normal tissues [31]. For example, a retrospective review of previously treated plans in the modern era demonstrated mean coverage of expertly defined consensus target volumes ranging from just 74-96\% [32]. Compromises in plan quality appear to be even more common in patients with immediate breast reconstruction, which is on the rise in North America [33,34]. In particular, coverage of the IMNs has been controversial, largely because IMN irradiation increases the dose to the heart [19]. Emerging data, however, support an oncologic benefit of IMN irradiation in some patients [5,6,35,36]. For example, a prospective population based cohort study recently showed a $3.7 \%$ absolute survival advantage at 8 years in patients 

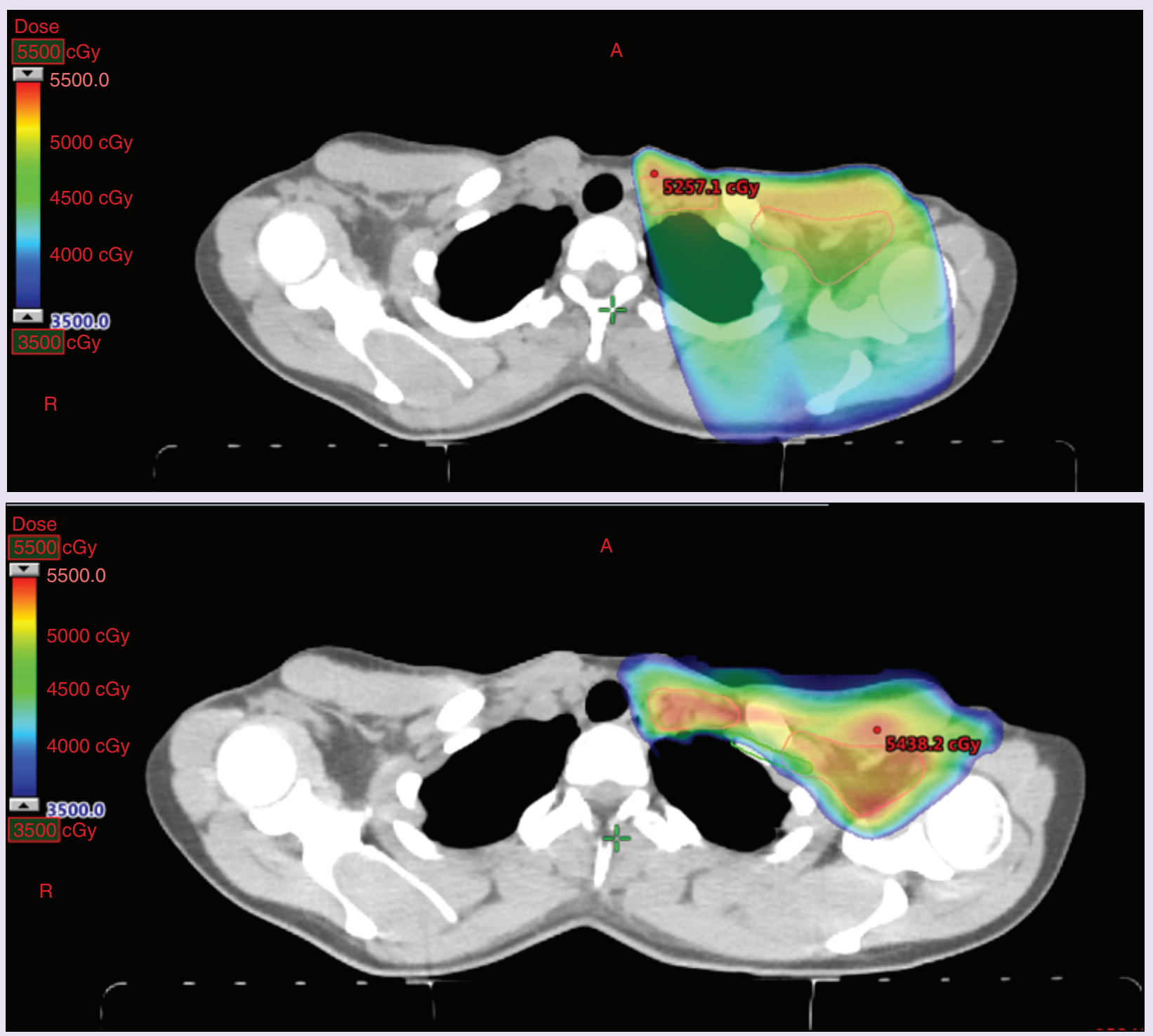

Figure 1. Proton therapy reduces the dose to the shoulder muscles, joint, soft tissues, and lung.

The upper panel shows a 3D conformal radiotherapy photon plan, while the lower panel shows a pencil-beam scanning proton plan for the same patient.

with right breast cancer who received IMN irradiation compared with left-sided breast cancer patients who did not [36]. Therefore, compromises in target coverage could increase the risk of recurrence [31]. Numerous dosimetric studies clearly support the advantage of PBT at improving target coverage while simultaneously decreasing dose to the heart, coronary vessels, lungs and contralateral normal tissue compared with photon advanced planning techniques. These advantages are evident whether the target is partial breast, whole breast/chest wall or breast/chest wall and regional lymph nodes (Table 1) [20,37-43]. A recent paper assessed the potential absolute gains with PBT compared with photon therapy in patients with left-sided breast cancer requiring comprehensive nodal irradiation. They modelled both the potential decrease in cardiac morbidity from reduced heart exposure as well as the potential reduction in breast cancer recurrence risk resulting from improved target coverage. Compared with photon therapy, the authors estimated that PBT may reduce the recurrence risk by up to $0.9 \%$ and lower the risk of an acute coronary event by age 80 by up to $2.9 \%$. Their results highlight the importance of comparative effectiveness research that 
not only assesses the impact of PBT in reducing adverse events, but also the potential improvements in disease control through more comprehensive target coverage [44].

\section{Clinical applications for PBT in breast cancer}

Accelerated partial breast irradiation

Accelerated Partial breast radiation (APBI) has emerged as an established adjuvant treatment option following lumpectomy in women with favorable, early stage breast cancer such as those over the age of 50 with small, lymph node negative, hormone receptor positive disease [45-48]. APBI offers many potential advantages over whole breast irradiation including shortening the course of treatment and reducing normal tissue exposure. While there are many options for ABPI delivery, external beam photon techniques are among the most frequently employed [49]. Some initial reports have showed acceptable cosmesis with external beam photon ABPI [50-52]. However, a multicenter randomized trial demonstrated increased rates of adverse cosmesis with external beam photon APBI compared with whole breast irradiation [53]. The APBI dose-fractionation regimen in that study remains the most commonly employed regimen in North America. Of note, deterioration of cosmesis has been correlated with irradiated breast volume [54-56]. The relationship between irradiated breast volume and cosmesis supports a potential advantage of PBT, which markedly lowers the volume of normal breast exposed [57-59]. PBT may also extend APBI as an option for some women, such as those with a large or unfavorably situated seroma [60]. In addition, PBT APBI reduces the dose to the heart, lungs, chest wall and pectoralis muscles compared with other APBI techniques [57-59].

Published experience of APBI with PBT has demonstrated high rates of tumor control [61-63]. Two series with long-term follow-up presented conflicting cosmetic outcomes, likely due to differences in technique and dosefractionation schedules. The Massachusetts General Hospital reported higher rates of fibrosis, telangiectasia and impaired cosmetic outcome with PBT compared with photons or mixed photons and electron APBI. At 7 years, the rate of telangiectasia, pigmentation changes and other late skin toxicities with PBT was 69, 54 and 62\%, respectively. Physician reported cosmesis was judged as fair in 38\% [62]. Patients were treated with doses of 32 Gy delivered over eight fractions delivered twice daily. For many patients, a single passively scattered proton field was delivered per day, which may increase the dose and biological effect on the skin. The authors suggested that this technical consideration could account for the impaired cosmesis seen with PBT study. In contrast, authors from Loma Linda reported on 100 patients treated to $40 \mathrm{~Gy}$ (relative biological effectiveness, RBE) over 10 fractions delivered once daily using 2-4 beams for planning. They reported favorable cosmetic outcomes, with $90 \%$ judged as good to excellent through 5 years of follow-up [63]. An additional Phase II experience of 30 treated proton patients supports the favorable toxicity profile of proton APBI when delivered with two or more fields per day, with good to excellent cosmesis noted among all but one patient treated with two fields [61].

\section{Whole breast without RNI}

There are limited data available on treatment outcomes of whole breast PBT without RNI. Dosimetric studies do support a potential benefit of PBT in reduction of heart, cardiac substructure and lung doses [41,64]. Patients with bilateral breast cancer, unfavorable anatomy and left-sided disease may be most likely to benefit from this approach (Figure 2). There is increased enthusiasm for investigating PBT after breast conserving surgery with the recent emergence of modern pencil-beam scanning PBT. Pencil-beam scanning PBT enables skin sparing similar to photon therapy, something that was not possible with previous passively scattered proton delivery technology. At the Mayo Clinic, a randomized Phase II trial is exploring the safety and efficacy of a novel five fractions proton and photon regimen for whole breast (without nodal) irradiation. This and other studies will shed more light on the potential role of whole breast PBT, including the optimal dose and fractionation. Ongoing proton therapy clinical trials are shown in Table 2.

\section{Whole breast/chest wall \& RNI}

A small number of patients treated with whole breast plus RNI have been reported in the literature [65]. However, due to the small numbers and short follow-up, no clear conclusions can be made regarding toxicity, long-term cosmesis or optimal techniques for delivery. Nevertheless, patients who have undergone breast conserving surgery are eligible for the Radiotherapy Comparative Effectiveness (RADCOMP) Consortium Pragmatic Phase III Randomized Trial of Proton versus Photon Therapy if they have indications for comprehensive RNI. There is strong rationale to study the role of PBT in patients with indications for RNI as these patients appear to derive the greatest dosimetric advantages for target coverage and normal tissue sparing (Table 1). 
Table 2. Ongoing breast cancer proton therapy trials.

\begin{tabular}{|c|c|c|c|c|}
\hline Study number & Design & Eligibility & End points & Enrollment information \\
\hline NCT02603341 & $\begin{array}{l}\text { Multicenter, pragmatic, } \\
\text { randomized proton vs. photon } \\
\text { (RADCOMP consortium, RTOG } \\
3510 \text { ) } \\
\text { RT standard fractionated, 5-7 } \\
\text { weeks }\end{array}$ & $\begin{array}{l}\text { Non-Metastatic BC requiring } \\
\text { locoregional RT, including IMNs }\end{array}$ & $\begin{array}{l}1^{\circ} \text { : Comparative effectiveness of } \\
\text { proton versus photons in } \\
\text { reducing major cardiovascular } \\
\text { events } \\
2^{\circ} \text { : Disease control, quality of } \\
\text { life, survival, dose and QOL and } \\
\text { cardiac outcomes }\end{array}$ & $\begin{array}{l}\text { Estimated enrollment: } 1720 \\
\text { Start: } 2 / 2016 \\
\text { Estimated final collection date } \\
\text { for } 1^{\circ} \text { end point: } 11 / 2020 \\
\text { Estimated study completion: } \\
11 / 2030\end{array}$ \\
\hline NCT02783690 & $\begin{array}{l}\text { Mayo Clinic, Phase II randomized } \\
15 \text { versus } 25 \text { fractions pencil } \\
\text { beam scanning proton post } \\
\text { mastectomy } \\
\text { RT is short course versus standard } \\
\text { course }\end{array}$ & $\begin{array}{l}\text { Nonmetastatic, noninflammatory } \\
\text { BC, with indications for PMRT } \\
\text { including regional nodal } \\
\text { irradiation }\end{array}$ & $\begin{array}{l}1^{\circ}: 24 \text { month complication rate } \\
\text { of grade } 3 \text { or higher AE or } \\
\text { unplanned surgical intervention } \\
2^{\circ}: \text { Acute toxicity, late toxicity, } \\
\text { QOL, cosmesis, IBTR, DFS, OS }\end{array}$ & $\begin{array}{l}\text { Estimated enrollment: } 82 \\
\text { Start: } 5 / 2016 \\
\text { Estimated final collection date } \\
\text { for } 1^{\circ} \text { end point: } 9 / 2020 \\
\text { Estimated study completion: } \\
9 / 2025\end{array}$ \\
\hline NCT03339934 & $\begin{array}{l}\text { Mayo Clinic, Phase II randomized } \\
5 \text { versus } 15 \text { fractions whole } \\
\text { breast RT } \\
\text { Photons and protons allowed } \\
\text { Optional boost to the } \\
\text { lumpectomy cavity in both arms }\end{array}$ & $\begin{array}{l}\text { Stage } 0-111 \text {, requiring whole } \\
\text { breast radiation post breast } \\
\text { conserving surgery. No } \\
\text { comprehensive regional nodal } \\
\text { irradiation }\end{array}$ & $\begin{array}{l}1^{\circ}: 24 \text { month complication rate } \\
\text { of hypofractionated RT versus } \\
\text { conventional } \\
2^{\circ}: \text { Acute and late toxicity, Local } \\
\text { control, DFS, OS }\end{array}$ & $\begin{array}{l}\text { Estimated enrollment: } 82 \\
\text { Start: } 11 / 2017 \\
\text { Estimated final collection date } \\
\text { for } 1^{\circ} \text { end point: } 11 / 2022 \\
\text { Estimated study completion: } \\
7 / 2023\end{array}$ \\
\hline NCT01758445 & $\begin{array}{l}\text { Multi-center, Phase II, } \\
\text { post-operative cardiac sparing RT } \\
\text { for breast cancer. } \\
\text { RT is standard fractionated }\end{array}$ & $\begin{array}{l}\text { Stage II/III, requiring post- } \\
\text { operative loco-regional RT }\end{array}$ & $\begin{array}{l}1^{\circ}: 5 \text { year acute and late toxicities } \\
\text { from PBT } \\
2^{\circ}: \text { Dosimetry comparison, LC, } \\
\text { DFS, OS, correlates of } \\
\text { dose/toxicity, quality of life }\end{array}$ & $\begin{array}{l}\text { Estimated enrollment: } 220 \\
\text { Start: } 2 / 2013 \text {, } \\
\text { Estimated final collection date } \\
\text { for } 1^{\circ} \text { end point: } 1 / 2022 \\
\text { Estimated study completion: } \\
1 / 2030\end{array}$ \\
\hline NCT02725840 & $\begin{array}{l}\text { University of Florida, proton or } \\
\text { photon observational cohort } \\
\text { RT is standard fractionated }\end{array}$ & $\begin{array}{l}\text { Stage } \mathrm{I}-\mathrm{III} \mathrm{BC} \text {, requiring } \\
\text { locoregional radiation }\end{array}$ & $\begin{array}{l}1^{\circ}: \text { Change in CT scans, blood } \\
\text { cytokines post radiation, proton } \\
\text { versus photon } \\
2^{\circ}: \text { Compare proton versus } \\
\text { photon long-term clinical grade } 2 \\
\text { or higher lung toxicity }<\mathrm{OS}\end{array}$ & $\begin{array}{l}\text { Estimated enrollment: } 55 \\
\text { Start: } 5 / 2016 \\
\text { Estimated final collection date } \\
\text { for } 1^{\circ} \text { end point: } 4 / 2021 \\
\text { Estimated study completion: } \\
4 / 2021\end{array}$ \\
\hline NCT03270072 & $\begin{array}{l}\text { Massachusetts General Hospital, } \\
\text { observational study of } \\
\text { institutional patients on RTOG } \\
3510\end{array}$ & $\begin{array}{l}\text { Stage II/III, receiving photons or } \\
\text { protons as part of RTOG } 3510\end{array}$ & $\begin{array}{l}1^{\circ} \text { : Change in global longitudinal } \\
\text { strain } \\
2^{\circ}: \text { LVEF, CT changes in lung, arm } \\
\text { lymphedema, thyroid } \\
\text { dysfunction, cosmesis }\end{array}$ & $\begin{array}{l}\text { Estimated enrollment: } 100 \\
\text { Start: } 10 / 2017 \\
\text { Estimated final collection date } \\
\text { for } 1^{\circ} \text { end point: } 7 / 2022 \\
\text { Estimated study completion: } \\
7 / 2027\end{array}$ \\
\hline NCT01839838 & $\begin{array}{l}\text { University of Pennsylvania, Phase } \\
\text { II APBI } \\
\text { RT not listed }\end{array}$ & Stage 0-IIA BC, eligible for APBI & $1^{\circ}:$ Number of adverse events & $\begin{array}{l}\text { Estimated enrollment: } 57 \\
\text { Start: } 4 / 2013 \\
\text { Estimated completion of } 1^{\circ} \text { end } \\
\text { point: } 4 / 2024\end{array}$ \\
\hline NCT03340402 & $\begin{array}{l}\text { Massachusetts General Hospital, } \\
\text { pilot study of ABPI delivered } \\
\text { pre-operatively } \\
\text { RT is five fractions }\end{array}$ & Triple negative $\mathrm{BC}$, clinical T1NO & $\begin{array}{l}1^{\circ}: \text { cumulative incidence of grade } \\
3 \text { or higher acute dermatitis } \\
2^{\circ}: \text { Margins needed identified at } \\
\text { resection, adverse events, } \\
\text { pathologic response, local failure } \\
\text { rates }\end{array}$ & $\begin{array}{l}\text { Estimated enrollment: } 20 \\
\text { Estimated start: } 12 / 2017 \\
\text { Estimated final collection date } \\
\text { for } 1^{\circ} \text { end point: } 11 / 2020 \\
\text { Estimation study completion: } \\
11 / 2023\end{array}$ \\
\hline NCT01245712 & $\begin{array}{l}\text { MD Anderson, single group } \\
\text { assignment to proton APBI } \\
\text { RT is } 3.4 \text { Gy twice daily for } 10 \\
\text { fractions }\end{array}$ & Stage $0-2 B C$, eligible for $A B P I$ & $\begin{array}{l}1^{\circ}: \text { patient reported cosmesis } \\
\text { score at } 1 \text { year } \\
2^{\circ}: \text { Acute grade } 3 \text { or higher } \\
\text { dermatitis, local control }\end{array}$ & $\begin{array}{l}\text { Estimated enrollment: } 200 \\
\text { Start: } 11 / 2010 \\
\text { Estimated final collection date } \\
\text { for } 1^{\circ} \text { end point: } 11 / 2021 \\
\text { Estimation study completion: } \\
11 / 2021\end{array}$ \\
\hline NCT01766297 & $\begin{array}{l}\text { Multicenter, Phase II proton } \\
\text { therapy partial breast RT }\end{array}$ & Stage 0-2 BC, eligible for ABPI & $\begin{array}{l}1^{\circ}: \text { Freedom from ipsilateral } \\
\text { breast recurrence } \\
2^{\circ}: \text { Acute and late toxicity, } \\
\text { dosimetry, quality of life }\end{array}$ & $\begin{array}{l}\text { Estimated enrollment: } 42 \\
\text { Start: } 2 / 2013 \\
\text { Estimated final collection date } \\
\text { for } 1^{\circ} \text { end point: } 1 / 2022 \\
\text { Estimated completion: } 1 / 2030\end{array}$ \\
\hline NCT00614172 & $\begin{array}{l}\text { Loma Linda, Phase II single arm } \\
\text { APBI proton } \\
\text { RT once daily, for ten fractions }\end{array}$ & Early stage, eligible for APBI & $\begin{array}{l}1^{\circ}: \text { Survival and recurrence rates } \\
2^{\circ}: \text { Toxicity and cosmetic results, } \\
\text { local control }\end{array}$ & $\begin{array}{l}\text { Estimated enrollment: } 150 \\
\text { Start: } 2 / 2004 \\
\text { Estimated completion: } 2 / 2019\end{array}$ \\
\hline NCT01310530 & $\begin{array}{l}\text { Loma Linda, Phase II single arm } \\
\text { APBI proton } \\
\text { RT once daily for ten fractions }\end{array}$ & Early stage, eligible for APBI & $\begin{array}{l}1: 5 \text { year recurrence rate } \\
2^{\circ}: \text { Rate or BC recurrence of low } \\
\text { versus intermediate risk patients, } \\
\text { side effects, disease-free survival }\end{array}$ & $\begin{array}{l}\text { Estimated enrollment: } 150 \\
\text { Start: 5/2011 } \\
\text { Estimated completion: } 5 / 2023\end{array}$ \\
\hline
\end{tabular}




\begin{tabular}{|c|c|c|c|c|}
\hline Study number & Design & Eligibility & End points & Enrollment information \\
\hline NCT02453737 & $\begin{array}{l}\text { Mayo Clinic, Phase II three } \\
\text { fractions APBI delivered using } \\
\text { protons, photons, or } \\
\text { brachytherapy } \\
\text { RT modality patient/physician } \\
\text { choice } \\
\text { Proton APBI } 7.3 \text { Gy daily for } \\
\text { three fractions }\end{array}$ & Early stage, eligible for APBI & $\begin{array}{l}1^{\circ} \text { : Change in the rate of adverse } \\
\text { cosmesis (defined as fair or poor } \\
\text { cosmesis) compared with } \\
\text { baseline } \\
2^{\circ} \text { : Acute and late toxicity, } \\
\text { quality of life }\end{array}$ & $\begin{array}{l}\text { Estimated enrollment: } 198 \\
\text { Start: } 6 / 2015 \\
\text { Estimated completion: } 6 / 2020\end{array}$ \\
\hline
\end{tabular}

APBI: Accelerated partial breast irradiation; BC: Breast cancer; CT: Computed tomography; DFS: Disease-free survival; IBTR: Ipsilateral breast tumor recurrence; IMN: Internal mammary node; LVEF: Left ventricular ejection fraction; OS: Overall survival; PMRT: Post-mastectomy radiotherapy; QOL: Quality of life; RADCOMP: Radiotherapy comparative effectiveness; RT: Radiotherapy; RTOG: Radiation Therapy Oncology Group.

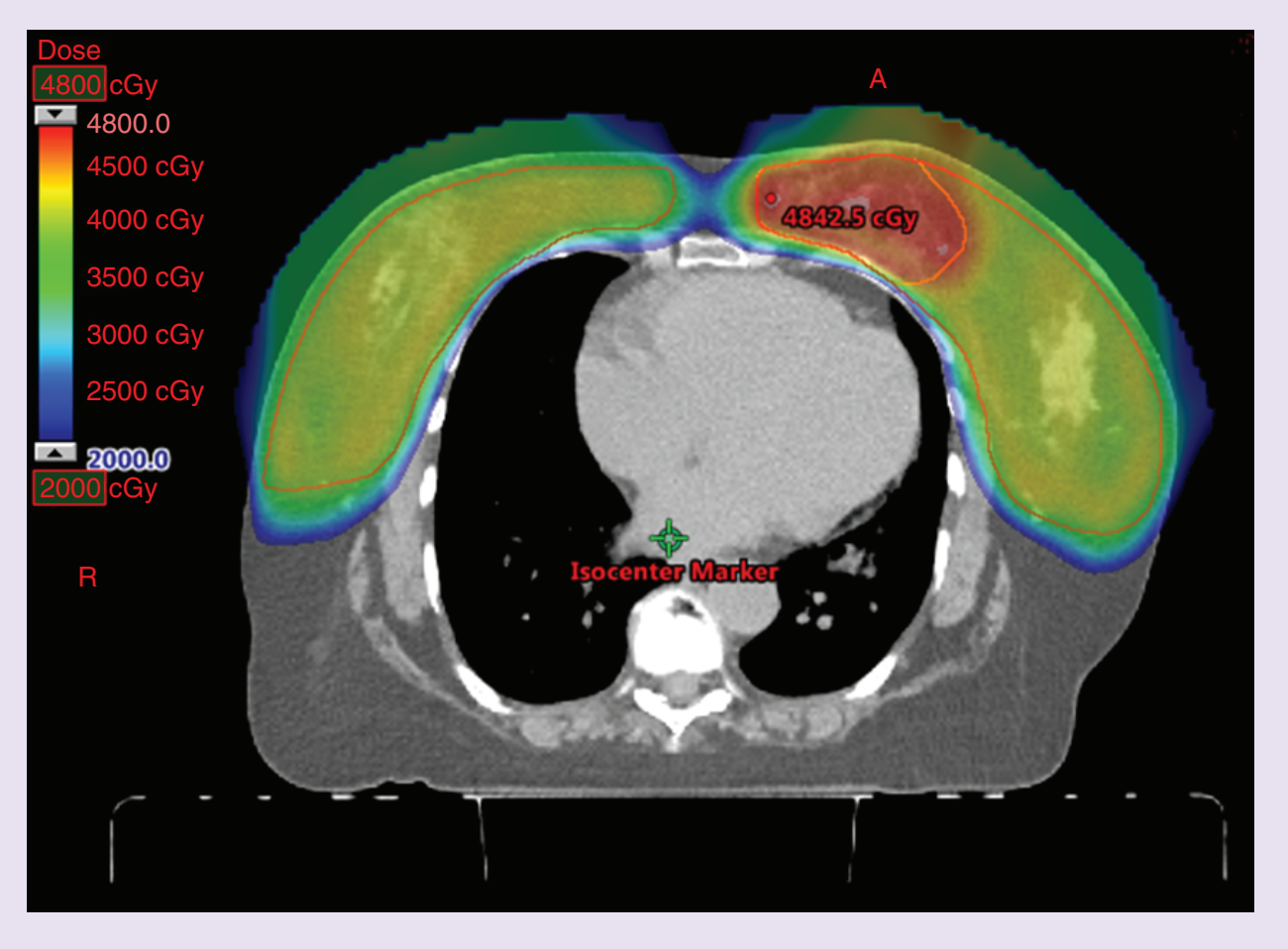

Figure 2. Proton therapy carves dose around complex clinical targets, minimizing normal tissue exposure.

A patient with bilateral breast cancer was treated with bilateral proton whole breast irradiation, with a boost to the left lumpectomy cavity. There is excellent target coverage with minimal exposure to the heart and lungs despite challenging anatomy.

Early clinical experience from several PBT centers is published on breast/chest wall and regional nodal PBT, the majority of whom were treated after mastectomy, with promising outcomes to date. Macdonald et al. reported an initial cohort of 12 patients treated with or without reconstruction in the post mastectomy setting. 11 of $12 \mathrm{were}$ left sided, and one patient had bilateral implants, which limited conventional planning options. The reported average mean heart dose was $0.44 \mathrm{~Gy}$. The ipsilateral lung V20 was $12.7 \%$. Acute skin toxicity outcomes were favorable, with no reported grade 3 toxicity. With 6 months of follow-up, no cases of chest wall toxicity or pneumonitis were reported [66].

Cuaron et al. reported on 30 patients treated with breast or chest wall and RNI. Target volume coverage was excellent, with a median V95 of $96.4 \%$. The median mean heart doses was 1.0 Gy for left-sided tumors, and the ipsilateral lung V20 was 16.5\%. Even with uniform scanning beams, skin toxicity appeared comparable to photons, with $71 \%$ experiencing grade 2 dermatitis and $28.6 \%$ experiencing moist desquamation. Acute grade 2 esophageal toxicity was $28.6 \%$, and resolved within 1 month of follow-up. Of note, the authors modified their target volumes 
around the esophagus after the first five patients to minimize overlap, and this appeared to reduce the esophagitis risk. With 9 months of follow-up, there were no rib fractures or reported chest wall toxicity [65].

Bradley et al. reported on outcomes for 18 patients with indications for RNI treated with PBT, eight of whom were irradiated with a combined PBT and photon technique [67]. PBT and conventional photon and or electron plans were prospectively developed for each patient. In each case, PBT plans better met dosimetric targets, significantly improving IMN coverage and lowering cardiac and lung doses. For example, the mean heart dose in left-sided patients was 5.9 versus 0.6 Gy for the conventional and PBT plans, respectively $(\mathrm{p}=0.004)$. Toxicities included grade 3 dermatitis $21 \%$, grade 2 chest wall pain $15 \%$ and grade 2 esophagitis $29 \%$.

The largest series included 93 patients and was recently reported with median follow-up of 15.5 months. The rate of grade 3 dermatitis was $12 \%$, with $8 \%$ requiring a treatment break. The rates of acute grade 1, 2 and 3 esophagitis were 31,33 and $0 \%$, respectively. Like others the authors noted that their PBT delivery techniques were optimized over the course of the study period, suggesting that outcomes will only continue to improve as the field gains experience with PBT [65,68]. In summary, these promising reports suggest that the acute toxicity profile of PBT compares favorably compares with photons. Long-term follow-up is needed to establish tumor control and delayed toxicity outcomes.

\section{Reirradiation}

Because of the heightened importance of sparing previously irradiated tissue and the high level of conformality that PBT affords, PBT is an attractive therapeutic modality for investigation in patients with indications for re-irradiation [69]. Data remain limited for PBT reirradiation in breast cancer [70]. A recently reported abstract of 22 patients undergoing reirradiation of the chest wall showed acceptable toxicity at 15 months. Just two patients developed grade 3 chest wall fibrosis and three patients experienced delayed wound healing. At last follow-up, 13 patients reported grade 1 chest wall pain [71].

Recently, the Radiation Therapy Oncology Group (RTOG) reported initial outcomes of a Phase II trial examining photon partial breast reirradiation after repeat lumpectomy for in-breast recurrence following previous whole breast irradiation. Excellent local control with acceptable early toxicity was observed [72]. An additional re-irradiation series with brachytherapy has also reported favorable results [73]. Mature data are still needed to establish repeat lumpectomy with APBI as a valid alternative to mastectomy for some women ipsilateral breast tumor recurrence following breast conserving therapy. However, PBT may be a promising modality to investigate in this setting to enable further reduction in the volume of re-irradiated nontarget breast and other normal tissues.

\section{Potential challenges}

With the promise of PBT come unique challenges, both logistical and technical, that warrant further discussion.

\section{Target localization}

Photons are slowly attenuated as they travel through tissue. Therefore, standard photon fields used to treat breast cancer may still deliver significant dose to nodal basins that are potentially at risk of harboring microscopic disease, even if they are not intentionally targeted [74]. For example, clinical target volumes according to the RTOG breast cancer atlas omit coverage of the posterolateral supraclavicular fossa (posterior triangle), yet a standard anterioroblique supraclavicular photon therapy field used to target the RTOG supraclavicular target volume will still cover the posterior triangle with a dose expected to control microscopic disease. In contrast, due to much steeper dose gradients, this area is unlikely to receive a meaningful dose with PBT if not specifically targeted. Recent studies suggest that the posterior triangle is a common site of supraclavicular nodal metastases [75,76]. As such, we strongly consider coverage of this area in patients with indications for RNI. In addition, based on these data, the RADCOMP consortium randomized trial of proton versus photon therapy has included the posterior triangle as an optional volume [75-77]. As PBT is investigated for whole breast irradiation, researchers will also need to contemplate the implications of the heightened conformality on axillary management. Standard photon tangential whole breast irradiation fields also deliver dose to a portion of the axilla. In a recent study, women who underwent lumpectomy and sentinel lymph node dissection with 1-2 positive nodes had low rates of axillary failure without completion axillary lymph node dissection [78]. The low rate of axillary failure may in part be due to intentional or incidental irradiation of the axilla as a component of whole breast irradiation [79]. With PBT, targeting of the whole breast alone would be a de-escalation of axillary therapy compared with photon therapy as the rapid dose fall off with 
PBT results in minimal dose to the axillary nodes. Therefore, when whole breast PBT is planned, physicians must carefully consider which axillary lymph node levels, if any, should be targeted under each clinical scenario.

\section{Treatment uncertainties}

Protons are more sensitive to some interfraction and intrafraction setup errors and changes in target volume over the course of treatment. For example, differences in position of the breast, implant, or tissue expander may have a greater impact on the quality of PBT delivery than conventional breast photon fields. In addition, changes in breast/chest wall shape due to swelling associated with acute treatment-related inflammation or the resolution of a postoperative seroma over can also impact target coverage and normal tissue sparing. These uncertainties should be scrutinized and can be generally mitigated by measures taken during treatment planning, setup and treatment delivery, as previously described $[80,81]$.

\section{Relative biological effectiveness}

RBE is the ratio of the dose of two radiation treatments, such as photons and protons, which causes the same level of biological effect [82]. A fixed RBE of 1.1 has historically been utilized for PBT in clinical practice based on available in vitro and in vivo data on the biologic effect of protons at the middle of the therapeutic radiation distribution or SOBP [83]. However, emerging data suggest that the RBE of protons is greater at the distal end of the proton range. If not accounted for in breast cancer PBT, this 'biologic range extension' could result in greater biologic effect (i.e., toxicity) beyond the target at the ribs, lung and heart. In the case of pencil beam scanning PBT delivered with multiple beams to a target, there may also be significant RBE heterogeneity throughout the target and normal tissues. RBE depends on a number of physical and biological parameters. There remains uncertainty as to how RBE at the end of range should be modeled and accounted for in breast cancer treatment planning, an important area for future investigation in the laboratory and in the clinic. Close clinical follow-up and a 'data-pooling culture' enabling correlation of individual treatment planning information with long-term clinical outcomes of large numbers of patients will be needed to better understand the impact of variations in RBE on PBT [84].

\section{Cost, access \& evidence development}

One deterrent of PBT development has been the higher cost of delivery compared with conventional photon techniques [85]. PBT requires considerable up-front capital investment. Therefore, the expense of treatment is generally higher [86]. One exception is APBI, with the cost of PBT comparing favorably with other accelerated techniques [87]. The cost-effectiveness of PBT is difficult to study, in part because of a paucity of long-term clinical outcomes and toxicity data [88]. The RADCOMP randomized Phase III study comparing photons versus protons for patients with indications for nodal irradiation is an important multi-institutional study ongoing with a primary end point of 10 years major cardiovascular events. Of note, most RT-induced major cardiovascular events and secondary malignancies occur greater than 10 years from treatment. In addition, the rapid pace of research and technological advances in the emerging PBT field is reducing cost and improving treatment delivery [89,90]. The recent arrival of skin-sparing pencil-beam scanning PBT for breast cancer is just one such advance $[80,81]$. Therefore, a multipronged approach including carefully designed randomized clinical trials, cohort studies and population-based analyses will be important to fine-tune PBT for breast cancer and enable a more complete picture of long-term clinical outcomes, quality of life and cost-effectiveness of state of the art PBT in the years ahead. Additionally, shorter courses of RT may reduce the gaps between the cost of photon and PBT delivery. At the Mayo Clinic, we have recently completed enrollment of a prospective trial exploring a novel three fractions APBI regimen and follow-up is ongoing (Table 2). In addition, accrual to a Phase II randomized trial examining the safety and efficacy of 15 fractions pencil-beam scanning PBT after mastectomy compared with the 'standard' 25 fractions course in patients requiring RNI is nearing completion, and a Phase II randomized trial comparing five fractions whole breast irradiation compared with the 'standard' 15 fractions course is now ongoing.

Finally, despite PBT being a US FDA-approved treatment modality with clear dosimetric advantages that are highly correlated with important toxicity end points, many insurance carriers do not cover PBT, even as part of a clinical trial [91]. Addressing this problem with creative, patient-centered solutions involving all stakeholders will be crucial to avoid hindering evidence development for an emerging treatment with significant potential to improve long-term patient outcomes [92]. 


\section{Conclusion \& future perspective}

The burgeoning field of breast cancer PBT is in its infancy. The improved target coverage and normal tissue avoidance over conventional photon techniques are well established. Presently, promising PBT applications for both early and advanced stage breast cancer patients are emerging, with potential to improve the therapeutic ratio. Careful attention to target volume delineation and strategies to mitigate inherent uncertainties associated with breast RT are important. There are exciting opportunities to improve treatment delivery, optimize schedules, refine patient selection and understand the unique radiobiology of PBT that will impact patient care. This work and robust comparative effectiveness research will establish the future role for PBT for breast cancer in the years ahead.

Acknowledgements

The authors would like to thank NB Remmes for his thoughtful review.

Financial \& competing interests disclosure

RW Mutter is supported by the American Society for Radiation Oncology, the National Cancer Institute of the NIH under award number P50CA116201, the Lead Academic Participating Site (LAPS) program under award number 5U10CA180790, K12 HD065987, HALT Cancer at X and the Lawrence W and Marilyn Matteson Fund in Cancer Research. KS Corbin is supported by the Lawrence W and Marilyn Matteson Fund in Cancer Research. The authors have no other relevant affiliations or financial involvement with any organization or entity with a financial interest in or financial conflict with the subject matter or materials discussed in the manuscript apart from those disclosed.

No writing assistance was utilized in the production of this manuscript.

Open access

This work is licensed under the Creative Commons Attribution 4.0 License. To view a copy of this license, visit http://creativecomm ons.org/licenses/by/4.0/

\section{References}

1. Siegel RL, Miller KD, Fedewa SA et al. Colorectal cancer statistics, 2017. CA Cancer J. Clin. 67, 177-193 (2017).

2. Mittmann N, Seung SJ, Liu N et al. Population-based utilization of radiation therapy by a Canadian breast cancer cohort. Curr. Oncol. 21, e715-e717 (2014).

3. Darby S, McGale P, Correa C et al. Effect of radiotherapy after breast-conserving surgery on 10 year recurrence and 15 year breast cancer death: meta-analysis of individual patient data for 10,801 women in 17 randomised trials. Lancet 378, 1707-1716 (2011).

4. Fisher B, Anderson S, Bryant J et al. Twenty-year follow-up of a randomized trial comparing total mastectomy, lumpectomy, and lumpectomy plus irradiation for the treatment of invasive breast cancer. N. Engl. J. Med. 347, 1233-1241 (2002).

5. Whelan TJ, Olivotto IA, Parulekar WR et al. Regional nodal irradiation in early-stage breast cancer. N. Engl. J. Med. 373, 307-316 (2015).

6. Poortmans PM, Collette S, Kirkove C et al. Internal mammary and medial supraclavicular irradiation in breast cancer. N. Engl. J. Med. 373, 317-327 (2015)

7. McGale P, Taylor C, Correa C et al. Effect of radiotherapy after mastectomy and axillary surgery on 10 year recurrence and 20 year breast cancer mortality: meta-analysis of individual patient data for 8135 women in 22 randomised trials. Lancet 383, 2127-2135 (2014).

8. Pierce SM, Recht A, Lingos TI et al. Long-term radiation complications following conservative surgery (CS) and radiation therapy (RT) in patients with early stage breast cancer. Int. J. Radiat. Oncol. Biol. Phys. 23, 915-923 (1992).

9. Meric F, Buchholz TA, Mirza NQ et al. Long-term complications associated with breast-conservation surgery and radiotherapy. Ann. Surg. Oncol. 9, 543-549 (2002).

10. Schaapveld M, Visser O, Louwman MJ et al. Risk of new primary nonbreast cancers after breast cancer treatment: a Dutch population-based study. J. Clin. Oncol. 26, 1239-1246 (2008).

11. Runowicz CD, Leach CR, Henry NL et al. American Cancer Society/American Society of Clinical Oncology Breast Cancer Survivorship Care Guideline. J. Clin. Oncol. 34, 611-635 (2016).

12. Wilson RR. Radiological use of fast protons. Radiology 47, 487-491 (1946).

13. Giordano SH, Kuo YF, Freeman JL, Buchholz TA, Hortobagyi GN, Goodwin JS. Risk of cardiac death after adjuvant radiotherapy for breast cancer. J. Natl Cancer Inst. 97, 419-424 (2005).

14. Clarke M, Collins R, Darby S et al. Effects of radiotherapy and of differences in the extent of surgery for early breast cancer on local recurrence and 15 year survival: an overview of the randomised trials. Lancet 366, 2087-2106 (2005).

15. Darby SC, Ewertz M, McGale P et al. Risk of ischemic heart disease in women after radiotherapy for breast cancer. N. Engl. J. Med. 368, 987-998 (2013). 
16. van den Bogaard VA, Ta BD, van der Schaaf A et al. Validation and modification of a prediction model for acute cardiac events in patients with breast cancer treated with radiotherapy based on three-dimensional dose distributions to cardiac substructures. J. Clin. Oncol. 35, 1171-1178 (2017).

17. Taylor C, Correa C, Duane FK et al. Estimating the risks of breast cancer radiotherapy: evidence from modern radiation doses to the lungs and heart and from previous randomized trials. J. Clin. Oncol. 35, 1641-1649 (2017).

18. Cahlon O, Khan AJ. Cardiac toxicity: the more we learn, the less we know. Int. J. Radiat. Oncol. Biol. Phys. 99, 1162-1165 (2017).

19. Taylor CW, Wang Z, Macaulay E, Jagsi R, Duane F, Darby SC. Exposure of the heart in breast cancer radiation therapy: a systematic review of heart doses published during 2003 to 2013. Int. J. Radiat. Oncol. Biol. Phys. 93, 845-853 (2015).

20. Ares $\mathrm{C}$, Khan $\mathrm{S}$, Macartain AM et al. Postoperative proton radiotherapy for localized and locoregional breast cancer: potential for clinically relevant improvements? Int. J. Radiat. Oncol. Biol. Phys. 76, 685-697 (2010).

21. Marks LB, Bentzen SM, Deasy JO et al. Radiation dose-volume effects in the lung. Int. J. Radiat. Oncol. Biol. Phys. 76, S70-S76 (2010).

22. Neugut AI, Murray T, Santos J et al. Increased risk of lung cancer after breast cancer radiation therapy in cigarette smokers. Cancer 73 , 1615-1620 (1994).

23. Kaufman EL, Jacobson JS, Hershman DL, Desai M, Neugut AI. Effect of breast cancer radiotherapy and cigarette smoking on risk of second primary lung cancer. J. Clin. Oncol. 26, 392-398 (2008).

24. Levangie PK, Drouin J. Magnitude of late effects of breast cancer treatments on shoulder function: a systematic review. Breast Cancer Res. Treat. 116, 1-15 (2009).

25. Farace P, Deidda MA, Amichetti M. Axillary irradiation omitting axillary dissection in breast cancer: is there a role for shoulder-sparing proton therapy? Br. J. Radiol. 88, 20150274 (2015).

26. Burt LM, Ying J, Poppe MM, Suneja G, Gaffney DK. Risk of secondary malignancies after radiation therapy for breast cancer: comprehensive results. Breast 35, 122-129 (2017).

27. Ng J, Shuryak I. Minimizing second cancer risk following radiotherapy: current perspectives. Cancer Manag. Res. 7, 1-11 (2015).

28. Abo-Madyan Y, Aziz MH, Aly MM et al. Second cancer risk after 3D-CRT, IMRT and VMAT for breast cancer. Radiother. Oncol. 110, 471-476 (2014).

29. Berrington de Gonzalez A, Curtis RE, Gilbert E et al. Second solid cancers after radiotherapy for breast cancer in SEER cancer registries. Br. J. Cancer 102, 220-226 (2010).

30. Schneider U, Lomax A, Pemler P et al. The impact of IMRT and proton radiotherapy on secondary cancer incidence. Strablenther. Onkol. 182, 647-652 (2006).

31. Thorsen LB, Thomsen MS, Berg M et al. CT-planned internal mammary node radiotherapy in the DBCG-IMN study: benefit versus potentially harmful effects. Acta Oncol. 53, 1027-1034 (2014).

32. Fontanilla HP, Woodward WA, Lindberg ME et al. Current clinical coverage of Radiation Therapy Oncology Group-defined target volumes for postmastectomy radiation therapy. Pract. Radiat. Oncol. 2, 201-209 (2012).

33. Jagsi R, Jiang J, Momoh AO et al. Trends and variation in use of breast reconstruction in patients with breast cancer undergoing mastectomy in the United States. J. Clin. Oncol. 32, 919-926 (2014).

34. Motwani SB, Strom EA, Schechter NR et al. The impact of immediate breast reconstruction on the technical delivery of postmastectomy radiotherapy. Int. J. Radiat. Oncol. Biol. Phys. 66, 76-82 (2006).

35. Haffty BG, Whelan T, Poortmans PM. Radiation of the internal mammary nodes: is there a benefit? J. Clin. Oncol. 34, 297-299 (2016).

36. Thorsen LB, Offersen BV, Dano H et al. DBCG-IMN: a population-based cohort study on the effect of internal mammary node irradiation in early node-positive breast cancer. J. Clin. Oncol. 34, 314-320 (2016).

37. Xu N, Ho MW, Li Z, Morris CG, Mendenhall NP. Can proton therapy improve the therapeutic ratio in breast cancer patients at risk for nodal disease? Am. J. Clin. Oncol. 37, 568-574 (2014).

38. Mast ME, Vredeveld EJ, Credoe HM et al. Whole breast proton irradiation for maximal reduction of heart dose in breast cancer patients. Breast Cancer Res. Treat. 148, 33-39 (2014).

39. Hernandez M, Zhang R, Sanders M, Newhauser W. A treatment planning comparison of volumetric modulated arc therapy and proton therapy for a sample of breast cancer patients treated with post-mastectomy radiotherapy. J. Proton Ther. 1(1), pii:119 (2015).

40. Jimenez RB, Goma C, Nyamwanda J et al. Intensity modulated proton therapy for postmastectomy radiation of bilateral implant reconstructed breasts: a treatment planning study. Radiother. Oncol. 107, 213-217 (2013).

41. Lin LL, Vennarini S, Dimofte A et al. Proton beam versus photon beam dose to the heart and left anterior descending artery for left-sided breast cancer. Acta Oncol. 54, 1032-1039 (2015).

42. Patel SA, Lu HM, Nyamwanda JA et al. Postmastectomy radiation therapy technique and cardiopulmonary sparing: a dosimetric comparative analysis between photons and protons with free breathing versus deep inspiration breath hold. Pract. Radiat. Oncol. 7 , e377-e384 (2017). 
43. Fagundes M, Hug EB, Pankuch M et al. Proton therapy for local-regionally advanced breast cancer maximizes cardiac sparing. Int. J. Particle Ther. 1(4), 827-844 (2015).

44. Stick LB, Yu J, Maraldo MV et al. Joint estimation of cardiac toxicity and recurrence risks after comprehensive nodal photon versus proton therapy for breast cancer. Int. J. Radiat. Oncol. Biol. Phys. 97, 754-761 (2017).

45. Correa C, Harris EE, Leonardi MC et al. Accelerated partial breast irradiation: executive summary for the update of an ASTRO evidence-based consensus statement. Pract. Radiat. Oncol. 7, 73-79 (2017).

46. Coles CE, Griffin CL, Kirby AM et al. Partial-breast radiotherapy after breast conservation surgery for patients with early breast cancer (UK IMPORT LOW trial): 5 year results from a multicentre, randomised, controlled, Phase 3, non-inferiority trial. Lancet 390, 1048-1060 (2017).

47. Polgar C, Fodor J, Major T, Sulyok Z, Kasler M. Breast-conserving therapy with partial or whole breast irradiation: ten-year results of the Budapest randomized trial. Radiother. Oncol. 108, 197-202 (2013).

48. Strnad V, Ott OJ, Hildebrandt G et al. 5 year results of accelerated partial breast irradiation using sole interstitial multicatheter brachytherapy versus whole-breast irradiation with boost after breast-conserving surgery for low-risk invasive and in-situ carcinoma of the female breast: a randomised, Phase 3, non-inferiority trial. Lancet 387, 229-238 (2016).

49. Julian TB, Costantino JP, Vicini FA et al. Early toxicity results with 3-D conformal external beam therapy (CEBT) from the NSABP B-39/RTOG 0413 accelerated partial breast irradiation (APBI) Trial. Int. J. Radiat. Oncol. Biol. Phys. 81(2), (Suppl. 7), S7 (2011).

50. Chen PY, Wallace M, Mitchell C et al. Four-year efficacy, cosmesis, and toxicity using three-dimensional conformal external beam radiation therapy to deliver accelerated partial breast irradiation. Int. J. Radiat. Oncol. Biol. Phys. 76, 991-997 (2010).

51. Lei RY, Leonard CE, Howell KT et al. External beam accelerated partial breast irradiation yields favorable outcomes in patients with prior breast augmentation. Front. Oncol. 4, 154 (2014).

52. Bergom C, Prior P, Kainz K et al. A Phase I/II study piloting accelerated partial breast irradiation using CT-guided intensity modulated radiation therapy in the prone position. Radiother. Oncol. 108, 215-219 (2013).

53. Olivotto IA, Whelan TJ, Parpia $S$ et al. Interim cosmetic and toxicity results from RAPID: a randomized trial of accelerated partial breast irradiation using three-dimensional conformal external beam radiation therapy. J. Clin. Oncol. 31, 4038-4045 (2013).

54. Jagsi R, Ben-David MA, Moran JM et al. Unacceptable cosmesis in a protocol investigating intensity-modulated radiotherapy with active breathing control for accelerated partial-breast irradiation. Int. J. Radiat. Oncol. Biol. Phys. 76, 71-78 (2010).

55. Mukesh M, Harris E, Jena R, Evans P, Coles C. Relationship between irradiated breast volume and late normal tissue complications: a systematic review. Radiother. Oncol. 104, 1-10 (2012).

56. Liss AL, Ben-David MA, Jagsi R et al. Decline of cosmetic outcomes following accelerated partial breast irradiation using intensity modulated radiation therapy: results of a single-institution prospective clinical trial. Int. J. Radiat. Oncol. Biol. Phys. 89, 96-102 (2014).

57. Wang X, Amos RA, Zhang X et al. External-beam accelerated partial breast irradiation using multiple proton beam configurations. Int. J. Radiat. Oncol. Biol. Phys. 80, 1464-1472 (2011).

58. Kozak KR, Katz A, Adams J et al. Dosimetric comparison of proton and photon three-dimensional, conformal, external beam accelerated partial breast irradiation techniques. Int. J. Radiat. Oncol. Biol. Phys. 65, 1572-1578 (2006).

59. Taghian AG, Kozak KR, Katz A et al. Accelerated partial breast irradiation using proton beams: initial dosimetric experience. Int. J. Radiat. Oncol. Biol. Phys. 65, 1404-1410 (2006).

60. Weed DW, Edmundson GK, Vicini FA, Chen PY, Martinez AA. Accelerated partial breast irradiation: a dosimetric comparison of three different techniques. Brachytherapy 4, 121-129 (2005)

61. Chang JH, Lee NK, Kim JY et al. Phase II trial of proton beam accelerated partial breast irradiation in breast cancer. Radiother. Oncol. 108, 209-214 (2013).

62. Galland-Girodet S, Pashtan I, MacDonald SM et al. Long-term cosmetic outcomes and toxicities of proton beam therapy compared with photon-based 3-dimensional conformal accelerated partial-breast irradiation: a Phase 1 trial. Int. J. Radiat. Oncol. Biol. Phys. 90, 493-500 (2014).

63. Bush DA, Do S, Lum S et al. Partial breast radiation therapy with proton beam: 5 year results with cosmetic outcomes. Int. J. Radiat. Oncol. Biol. Phys. 90, 501-505 (2014).

64. Fogliata A, Bolsi A, Cozzi L. Critical appraisal of treatment techniques based on conventional photon beams, intensity modulated photon beams and proton beams for therapy of intact breast. Radiother. Oncol. 62, 137-145 (2002).

65. Cuaron JJ, Chon B, Tsai H et al. Early toxicity in patients treated with postoperative proton therapy for locally advanced breast cancer. Int. J. Radiat. Oncol. Biol. Phys. 92, 284-291 (2015).

66. Macdonald SM, Patel SA, Hickey S et al. Proton therapy for breast cancer after mastectomy: early outcomes of a prospective clinical trial. Int. J. Radiat. Oncol. Biol. Phys. 86, 484-490 (2013).

67. Bradley JA, Dagan R, Ho MW et al. Initial report of a prospective dosimetric and clinical feasibility trial demonstrates the potential of protons to increase the therapeutic ratio in breast cancer compared with photons. Int. J. Radiat. Oncol. Biol. Phys. 95, 411-421 (2016). 
68. Verma V, Iftekaruddin Z, Badar $\mathrm{N}$ et al. Proton beam radiotherapy as part of comprehensive regional nodal irradiation for locally advanced breast cancer. Radiother. Oncol. 123, 294-298 (2017).

69. Plastaras JP, Berman AT, Freedman GM. Special cases for proton beam radiotherapy: re-irradiation, lymphoma, and breast cancer. Semin. Oncol. 41, 807-819 (2014).

70. Wahl AO, Rademaker A, Kiel KD et al. Multi-institutional review of repeat irradiation of chest wall and breast for recurrent breast cancer. Int. J. Radiat. Oncol. Biol. Phys. 70, 477-484 (2008).

71. McGee LA, Iftekaruddin Z, Chang JHC et al. Postmastectomy chest wall reirradiation with proton therapy for breast cancer. Int. J. Radiat. Oncol. Biol. Phys. 99(2), (Suppl.), E34-E35 (2017).

72. Arthur DW, Moughan J, Kuerer HM et al. NRG Oncology/RTOG 1014: 3 year efficacy report from a Phase II study of repeat breast preserving surgery and 3D conformal partial breast re-irradiation (PBrI) for in-breast recurrence. Int. J. Radiat. Oncol. Biol. Phys. 96, 941 (2016).

73. Hannoun-Levi JM, Resch A, Gal J et al. Accelerated partial breast irradiation with interstitial brachytherapy as second conservative treatment for ipsilateral breast tumour recurrence: multicentric study of the GEC-ESTRO Breast Cancer Working Group. Radiother. Oncol. 108, 226-231 (2013).

74. Jethwa KR, Kahila MM, Hunt $\mathrm{KN}$ et al. Delineation of internal mammary nodal target volumes in breast cancer radiation therapy. Int. J. Radiat. Oncol. Biol. Phys. 97, 762-769 (2017).

75. Reed VK, Cavalcanti JL, Strom EA et al. Risk of subclinical micrometastatic disease in the supraclavicular nodal bed according to the anatomic distribution in patients with advanced breast cancer. Int. J. Radiat. Oncol. Biol. Phys. 71, 435-440 (2008).

76. Brown LC, Diehn FE, Boughey JC et al. Delineation of supraclavicular target volumes in breast cancer radiation therapy. In reply to Yang and Guo. Int. J. Radiat. Oncol. Biol. Phys. 93, 723-724 (2015).

77. Breast Contouring RADCOMP Consortium (2016). www.rtog.org/LinkClick.aspx?fileticket=eVB451KQ83M\%3d\&tabid=429

78. Giuliano AE, Ballman KV, McCall L et al. Effect of axillary dissection vs no axillary dissection on 10 year overall survival among women with invasive breast cancer and sentinel node metastasis: The ACOSOG Z0011 (Alliance) Randomized Clinical Trial. JAMA 318, 918-926 (2017).

79. Jagsi R, Chadha M, Moni J et al. Radiation field design in the ACOSOG Z0011 (Alliance) Trial. J. Clin. Oncol. 32, 3600-3606 (2014).

80. Mutter RW, Remmes NB, Kahila MM et al. Initial clinical experience of postmastectomy intensity modulated proton therapy in patients with breast expanders with metallic ports. Pract. Radiat. Oncol. 7, e243-e252 (2017).

81. Depauw N, Batin E, Daartz J et al. A novel approach to postmastectomy radiation therapy using scanned proton beams. Int. J. Radiat. Oncol. Biol. Phys. 91, 427-434 (2015).

82. Underwood T, Paganetti H. Variable proton relative biological effectiveness: how do we move forward? Int. J. Radiat. Oncol. Biol. Phys. 95, 56-58 (2016).

83. Paganetti H, Niemierko A, Ancukiewicz M et al. Relative biological effectiveness (RBE) values for proton beam therapy. Int. J. Radiat. Oncol. Biol. Phys. 53, 407-421 (2002).

84. Deasy JO, Bentzen SM, Jackson A et al. Improving normal tissue complication probability models: the need to adopt a "data-pooling" culture. Int. J. Radiat. Oncol. Biol. Phys. 76, S151-S154 (2010).

85. Lievens Y, Pijls-Johannesma M. Health economic controversy and cost-effectiveness of proton therapy. Semin. Radiat. Oncol. 23, 134-141 (2013).

86. Peeters A, Grutters JP, Pijls-Johannesma $\mathrm{M}$ et al. How costly is particle therapy? Cost analysis of external beam radiotherapy with carbon-ions, protons and photons. Radiother. Oncol. 95, 45-53 (2010).

87. Ovalle V, Strom EA, Godby J et al. Proton partial-breast irradiation for early-stage cancer: is it really so costly? Int. J. Radiat. Oncol. Biol. Phys. 95, 49-51 (2016).

88. Verma V, Mishra MV, Mehta MP. A systematic review of the cost and cost-effectiveness studies of proton radiotherapy. Cancer 122, 1483-1501 (2016).

89. Mohan R, Bortfeld T. Proton therapy: clinical gains through current and future treatment programs. Front. Radiat. Ther. Oncol. 43 , $440-464$ (2011).

90. Mansur DB. Incorporating a compact proton therapy unit into an existing National Cancer Institute-designated comprehensive cancer center. Expert Rev. Anticancer Ther. 14, 1001-1005 (2014).

91. Bekelman JE, Hahn SM. Reference pricing with evidence development: a way forward for proton therapy. J. Clin. Oncol. 32, 1540-1542 (2014).

92. ASTRO Model Policies: Proton Beam Therapy (PBT) (2017). www.astro.org/uploadedFiles/_MAIN_SITE/Daily_Practice/Reimbursem ent/Model_Policies/Content_Pieces/ASTROPBTModelPolicy.pdf 
